I Casa de Oswaldo Cruz (COC), Fundação Oswaldo Cruz (Fiocruz),

Rio de Janeiro, RJ, Brasil

lopes_47@hotmail.com

https://orcid.org/oooo-ooo I-6I I I-2645

Thiago da Costa Lopes'

\title{
O INSTITUTO DE CIÊNCIAS SOCIAIS E A SOCIOLOGIA NO RIO DE JANEIRO: ENTREVISTA COM ALZIRA ALVES DE ABREU
}

A entrevista que se vai ler foi concedida pela socióloga Alzira Alves de Abreu em dezembro de 20I8, no Rio de Janeiro, como parte da iniciativa da revista Sociologia \& Antropologia em rememorar as experiências pretéritas de ensino e pesquisa em ciências sociais da UFRJ por ocasião da comemoração dos 80 anos de existência de seu curso, completados em 20I9. Como o leitor poderá perceber, a trajetória de Alzira se entrelaça com momentos significativos por que passaram as ciências sociais no Rio de Janeiro em seus esforços de institucionalização acadêmica e consolidação enquanto campo disciplinar, especialmente com as atividades investigativas conduzidas no interior do Instituto de Ciências Sociais (ICS), centro de pesquisas da antiga Universidade do Brasil (atual UFRJ), criado em I958. Nesse sentido, seu depoimento, além de constituir fonte importante para o resgate da memória da instituição, fornece pistas sugestivas para os estudiosos interessados em ampliar a compreensão que se tem da história daquelas disciplinas na cidade.

Nascida em uma família de imigrantes portugueses de classe média, Alzira ingressou no curso de história e geografia da Faculdade Nacional de Filosofia (FNFi) da Universidade do Brasil em I954 (Abreu, 20I2). Na instituição, aproximou-se das ciências sociais sobretudo a partir da antropologia - cuja carga horária era considerável na grade curricular, sendo ministrada nos três primeiros anos do curso -, assistindo às aulas de Marina São Paulo de Vasconcellos, catedrática interina, e de Darcy Ribeiro, que então lecionava etnografia brasileira e língua tupi. Criada em I939, na vigência do Estado Novo, em substituição à 
Universidade do Distrito Federal, por iniciativa do ministro da Educação e Saúde Gustavo Capanema, a FNFi, cuja montagem contou com o envolvimento estreito de Alceu Amoroso Lima, expressiva liderança da intelectualidade católica leiga, esteve voltada prioritariamente para a formação de professores destinados ao ensino secundário, constituindo um desafio perene para os quadros da universidade a rotinização da pesquisa científica e o prosseguimento de uma carreira acadêmica em seu interior, e isto em razão de uma estrutura institucional percebida como frágil, pouco favorável à autonomia didática e administrativa (Schwartzman, Bomeny \& Costa, I984; Fávero, I989; Almeida, 200I; Oliveira, I995; Ferreira, 2013). Na segunda metade dos anos I950, período em que Alzira realizou sua graduação, tanto a pesquisa de natureza arquivística quanto o trabalho de campo permaneceram em segundo plano nos cursos da instituição (Ferreira, 20I3), informação que seu depoimento corrobora.

Não obstante esse cenário, as ciências sociais no Rio de Janeiro trilharam caminhos alternativos na busca de condições para a realização da investigação empírica sistemática. Os anos 1950 foram pródigos em projetos coletivos de grande envergadura, como o Projeto Unesco de Relações Raciais, e em iniciativas institucionais, como o Centro Brasileiro de Estudos Pedagógicos (CBPE) e o Centro Latino-americano de Pesquisas em Ciências Sociais (Clapcs), que acabaram por albergar as atividades de pesquisa em ciências sociais na cidade a partir da articulação entre atores, instituições e agendas investigativas locais, agências estrangeiras e organismos multilaterais, como a Unesco (Peixoto, 200I; Maio, I997). Os rumos que Alzira imprime à sua carreira ao final da graduação acompanham esse processo. Por intermédio de Darcy Ribeiro, com quem havia trabalhado enquanto aluna da FNFi, realizando levantamentos arquivísticos na Biblioteca Nacional, ela passa a atuar no CBPE, órgão criado em I 955 por Anísio Teixeira, diretor do Instituto Nacional de Estudos Pedagógicos, em colaboração com a Unesco, que visava prover subsídios ao planejamento das políticas educacionais do país com base na investigação do universo sociocultural de diferentes localidades e regiões brasileiras. Não apenas Darcy Ribeiro, que veio a ser coordenador de cursos de formação de pesquisadores sociais e diretor da Divisão de Estudos e Pesquisas Educacionais do CBPE, mas uma gama de importantes nomes das ciências sociais do período esteve vinculada ou desenvolveu projetos de pesquisa no âmbito da instituição, a exemplo de Luiz de Aguiar Costa Pinto, Bertram Hutchinson, Oracy Nogueira, Manuel Diégues Júnior e Florestan Fernandes, de modo que esta acabou se tornando um polo aglutinador de cientistas sociais nacionais, que atuavam em cidades como Rio de Janeiro e São Paulo, e estrangeiros (Oliveira, I995). Com a saída de Darcy Ribeiro, envolvido com a criação da Universidade de Brasília, e o clima de insegurança que se instala no CBPE após o golpe de I964, que instituiu o regime militar no país, Alzira transferiu suas atividades, graças à intermediação de Roberto Cardoso de Oliveira, antropólogo do Museu Nacional que conhecera naquela ins- 
tituição, para o Instituto de Ciências Sociais (ICS), trabalhando com pesquisa até a partida para o doutorado na França, em I969.

O depoimento de Alzira sobre sua experiência no ICS, que constitui o eixo principal da entrevista, assume particular relevo, em especial quando se considera que o exame dessa iniciativa, ainda pouco pesquisada e conhecida, pode servir para matizar as interpretações mais recorrentes sobre a história das ciências sociais no Rio de Janeiro, geralmente concebida, em suas contramarchas e dificuldades, em oposição à relativamente bem-sucedida experiência paulista de institucionalização universitária. Centro investigativo da Universidade do Brasil que ganhou corpo em I958, e que refletia o empenho de seus quadros em suprir as insuficiências da instituição no terreno da pesquisa, o ICS não esteve vinculado a nenhuma cadeira em particular, resultando, antes, dos esforço de cooperação interdisciplinar de professores da Faculdade Nacional de Filosofia, da Faculdade Nacional de Direito, da Faculdade de Ciências Econômicas e da Divisão de Antropologia do Museu Nacional. Por seu Conselho Diretor passaram nomes como Evaristo de Moraes Filho, Themístocles Cavalcanti, Luiz de Aguiar Costa Pinto, Luiz de Castro Faria, Victor Nunes Leal, Roberto Cardoso de Oliveira e Marina São Paulo de Vasconcellos, Darcy Ribeiro e Lineu de Albuquerque Mello.

Ao ingressar no corpo técnico de pesquisadores do instituto, que funcionava com base em recursos da própria universidade, Alzira passou a trabalhar, ao lado de Maria Luiza Carvalho Proença, que também pertencera aos quadros do CBPE, nas investigações sobre o empresariado brasileiro sob responsabilidade de Luciano Martins, sociólogo formado na Universidade do Brasil que havia sido contratado para atuar como professor do Curso de Desenvolvimento Econômico das cadeiras de sociologia da FNFi e da Faculdade Nacional de Ciências Econômicas (Martins, I968), cadeiras entre cujos responsáveis estava Costa Pinto. A fim de proceder a uma ampla radiografia do setor, identificando suas origens, composição social e padrões de comportamento econômico e político, a equipe de pesquisadores do ICS realizou levantamentos de dados oficiais dos maiores grupos empresariais nacionais, além de entrevistar e aplicar questionários a seus dirigentes. Em um segundo momento, o interesse dos estudiosos em compreender o envolvimento desses agentes com as políticas de desenvolvimento industrial das décadas de I930 e I940 levou Alzira à pesquisa em arquivos privados de atores que ocuparam posições-chave no governo brasileiro, como o de Getúlio Vargas.

Os estudos dirigidos por Martins, que contaram com recursos do Instituto Latino-Americano de Planificação Econômica e Social das Nações Unidas (Martins, I968, p. I66), constituíam, por sua vez, um desdobramento do amplo projeto de pesquisa coordenado por Maurício Vinhas de Queiroz acerca dos grupos multibilionários, nacionais e estrangeiros, em atuação no Brasil. Conforme indicou Villas Bôas (2019, p. 302), das discussões e seminários promovi- 
dos por esses pesquisadores participaram com frequência cientistas sociais vinculados à Universidade de São Paulo, como Florestan Fernandes, Fernando Henrique Cardoso e Francisco Weffort. José de Souza Martins, por recomendação de Cardoso, chegou a trabalhar nas pesquisas do ICS como assistente de Maurício, e parte dos seus achados foram utilizados na tese que defendeu na USP, sob a orientação de Florestan, tratando da formação do grupo econômico chefiado pelo conde Matarazzo. Ademais, por meio das pesquisas sobre o empresariado conduzidas no ICS, os sociólogos situados no Rio de Janeiro participaram dos acalorados debates em torno do desenvolvimento brasileiro, das possibilidades de que o país ingressasse no rol das nações modernas, galgando autonomia econômica e quebrando os laços de dependência com as grandes potências, temas que povoaram o imaginário dos anos I950 e ao qual as ciências sociais não permaneceram indiferentes (Villas Bôas, 2019, p. 302-303). Embora as teses de Fernando Henrique Cardoso tenham se tornando mais conhecidas a esse respeito (Rodrigues, 2009), os estudiosos do ICS enveredaram igualmente pela crítica à visão, então bastante difundida nos meios nacionalistas de esquerda, e adotada, grosso modo, nos anos I950, pelos quadros do Instituto Superior de Estudos Brasileiros (Iseb), instituição sediada no Rio de Janeiro, e pelo Partido Comunista Brasileiro, segundo a qual a denominada burguesia nacional constituía ator-chave nas transformações socioeconômicas que, com base em um processo de contínua e acelerada industrialização orientada pelo planejamento estatal, acabariam por levar à superação dos entraves ao desenvolvimento representados pelos interesses dos setores "arcaicos" da sociedade, ligados ao latifúndio agrário-exportador. Nesse caso, como os estudos de Martins (I968, p. I07-I6I) permitem entrever, esses pesquisadores contribuíram, ao lado de cientistas sociais em atuação em São Paulo, para problematizar a ideia de protagonismo histórico que o conceito de burguesia nacional pressupunha, assinalando os nexos de dependência que ligavam o empresariado brasileiro ao capital estrangeiro, ao Estado e aos grandes produtores agrícolas, bem como suas posturas tímidas frente aos ideais de reforma que, a princípio, deveria encampar, assumido a liderança do processo político. Ademais, de acordo com o sociólogo, a conjuntura pós-I964 já não autorizava perspectivas otimistas quanto às mudanças sociais e políticas que poderiam advir do desenvolvimento do país em moldes capitalistas (Martins, I968, p. I I-I4).

Tais indicações, relativas à amplitude das tomadas de posição crítica em face do nacional-desenvolvimentismo nas ciências sociais, que envolveram pesquisadores tanto do Rio quanto de São Paulo, são reforçadas pelo depoimento de Alzira. Elas nos lembram que, além das diferenças quanto às circunstâncias que marcaram seus respectivos esforços de institucionalização, exploradas pela bibliografia, houve trocas, conexões e circulação entre atores e instituições situados nas duas cidades, quadro intrincado que se abre à investigação quando nos afastamos das rígidas chaves dualistas de leitura, como aquelas que 
tenderam a opor, na história das ciências sociais, a experiência carioca, frequentemente pensada a partir do Iseb, à experiência paulista. ${ }^{\mathrm{I}}$

Incorporado ao Instituto de Filosofia e Ciências Sociais (Ifcs) com a Reforma Universitária de I967, o ICS não ficou imune à maré autoritária dos anos I960, e o recrudescimento do regime militar após o Ato Institucional n.5 produziu uma atmosfera de insegurança que repercutiu nos quadros da instituição, comprometendo a continuidade de suas atividades e o financiamento das pesquisas (Amorim, I999). Seguindo a trilha aberta por Luciano Martins, que desde 1968 se encontrava em Paris, cidade que recebeu diversos intelectuais brasileiros vivendo no exílio, como Celso Furtado, Alzira partiu para o doutorado na Université Paris-Descartes (Paris V). Entre I970 e I975, ela se dedicou, sob a orientação de François Bourricaud, estudioso da América Latina, a um exame da experiência do Iseb à luz dos estudos sobre os "grupos de interesse", concebidos como atores organizados que buscavam se colocar na posição de intermediários entre o Estado e diferentes segmentos da sociedade, funcionando como canal para a expressão de diferentes demandas junto às instâncias do poder (Abreu, I975).

A tese de Alzira, intitulada Nationalisme et action politique au Brésil: une étude sur l'Iseb, sugere que, a despeito do cenário adverso com que o ICS se defrontou, as discussões sobre desenvolvimento que transcorreram em seu interior tiveram repercussão nos anos subsequentes. Em seu trabalho, à semelhança de estudos produzidos na USP no mesmo período, como o de Caio Navarro de Toledo, Alzira buscava examinar criticamente a atuação do Iseb partindo daquelas leituras sociológicas sobre o desenvolvimento brasileiro mais céticas quanto aos papéis a ser desempenhados pelos grupos industriais nacionais. Em suas conclusões, ela observa que, contrariamente ao que preconizavam os ideólogos do nacional-desenvolvimentismo, os industriais não percebiam quaisquer contradições entre seus interesses e aqueles mantidos pelos setores agrários, enxergando-os, ao contrário, como importantes fontes de divisas para a incorporação de tecnologia estrangeira à produção local. Ademais, sua associação estreita com o capital estrangeiro fazia cair por terra as expectativas de maior autonomia nacional, aprofundando os vínculos de dependência com o capitalismo mundial (Abreu, I975, p. 301-302). Ao apontar para os limites do nacionalismo como instrumento ideológico de combate destinado a impulsionar as mudanças, Alzira se apoiava em análises sociológicas que, oriundas das pesquisas do ICS e da USP, buscavam fornecer, em substituição a modelos teóricos de desenvolvimento julgados por demais abstratos, etapistas e lineares, visões mais nuançadas acerca das circunstâncias históricas concretas que haviam presidido os surtos industrializantes do país (Abreu, I975, p. 256-262).

Além de fornecer elementos para o debate em torno do desenvolvimento, o ICS constituiu o espaço das primeiras experiências de pesquisa de cientistas sociais cujos trabalhos se tornaram conhecidos nas décadas seguintes, 
como Gilberto Velho, Yvonne Maggie e Alba Zaluar. Nomes que passaram pelo instituto também tiveram papel relevante, posteriormente, na conformação de centros de estudo, como foi o caso do Cpdoc, da Fundação Getulio Vargas, de cuja montagem participaram Celina Vargas do Amaral Peixoto, que estagiou no ICS, e a própria Alzira, que revela, em seu depoimento, a riqueza das experiências de pesquisa do instituto e a importância que teve, para a sua atividade profissional, o trabalho com arquivos privados iniciado no âmbito das investigações dirigidas por Luciano Martins. Iluminando um momento ainda pouco estudado da história das ciências sociais no Rio de Janeiro, a entrevista com Alzira oferece a oportunidade de rememorar o passado e, ao mesmo tempo, de refletir sobre questões de pesquisa que ainda hoje merecem ser exploradas.

Tiago da Costa Lopes. Boa tarde. Hoje é dia I8 de dezembro de 20I8. Estamos aqui a fim de conversar com a professora Alzira Alves de Abreu para a seção de Memória, da revista Sociologia \& Antropologia, sobretudo interessados em rastrear um pouco a história do ICS, futuro Ifcs, e do curso de ciências sociais da UFRJ. Para começar nossa conversa, é sempre interessante que se faça primeiro um panorama de sua formação. Quando a senhora chegou no curso?

Alzira Alves de Abreu. Fiz, na antiga Faculdade Nacional de Filosofia. Eu fiz curso de história e geografia.

T.C.L. Ainda era o curso de história e geografia oferecido conjuntamente?

A.A.A. Era sim. Quando terminei a faculdade, eu fui convidada por Darcy Ribeiro, que era o professor de antropologia da Faculdade Nacional de Filosofia, para trabalhar com ele no CBPE, Centro de Pesquisa e Documentação. Então trabalhei com Darcy muitos anos. Fiz pesquisa em educação. Quando Darcy foi embora para Brasília, criar a Universidade de Brasília, o CBPE ficou meio sem nada e acabou. Aí veio I964. Vamos lembrar que tudo começou a ficar muito ruim. A situação ficou muito ruim, e nós não tínhamos o que fazer lá. O que importa é que, quando chegou I964, nós estávamos muito mal no CBPE. Então Roberto Cardoso de Oliveira, que era do Museu Nacional, me convidou, junto com Maria Luiza de Carvalho Proença, para trabalhar com Luciano Martins no Instituto de Ciências Sociais, aqui na Marquês de Olinda.

A situação no CBPE estava muito ruim. Então aceitei. Nós fomos lá conversar com Luciano Martins, que estava começando uma pesquisa. O que eu posso contar é que eu fui ver com Luciano Martins o que ele estava fazendo. Era uma pesquisa sobre a tomada de decisão quanto ao desenvolvimento in- 
dustrial brasileiro. Na ocasião, ele dizia que eram dez decisões estratégicas para o desenvolvimento. E precisava de pessoas que fossem trabalhar com ele. Aceitei. Então, pedimos transferência de lá para o instituto e fui trabalhar nessa pesquisa. Luciano queria começar com a tomada de decisão e criação da indústria siderúrgica de Volta Redonda. Então lá fui eu trabalhar com Maria Luiza, que já morreu. É uma pena que não dê para ela contar a história. E o que era a pesquisa? Eu queria chamar a atenção disso. Nós fomos trabalhar em uma pesquisa numa época em que ainda não se usava muito trabalhar com arquivos. Luciano falava assim: "Nós temos que fazer a pesquisa sobre a criação de Volta Redonda. Como foi criado isso? Quem criou? Como é que saiu isso?"

T.C.L. A senhora diz nas ciências sociais?

A.A.A. Sim, nas ciências sociais. Luciano era das ciências sociais. Eu trabalhava com sociologia e antropologia. Então nós começamos a trabalhar. Como se criou Volta Redonda? Que história foi essa? De onde saiu isso? Isso é uma coisa importante. Nós fomos vendo que essa decisão tinha sido tomada no período de Getúlio. E como é que havia se tomado essa decisão de criar Volta Redonda? Então fomos procurar Alzira Vargas do Amaral Peixoto, que tinha o arquivo de Getúlio Vargas. Fomos consultar, para fazer essa pesquisa, o arquivo de Getúlio Vargas. Na ocasião, não tinha essa coisa de consultar arquivo privado. Quem fazia isso eram os americanos. Eu lembro que os pesquisadores americanos que vinham fazer pesquisa no Brasil já consultavam arquivos privados e já consultavam os arquivos na casa de dona Alzira Vargas.

T.C.L. Quem eram esses americanos?

A.A.A. Você vai pegar todos os pesquisadores americanos dessa época. Agora aqui eu não vou lembrar. Eles vão fazer pesquisa sobre o Brasil, sobre a história do Brasil do período.

T.C.L. São historiadores?

A.A.A. Historiadores e cientistas sociais. Eles já faziam isso. Eu lembro que, quando nós chegamos na casa de dona Alzira, perguntando se podíamos consultar o arquivo Vargas, ela disse que os americanos já tinham ido lá fazer isso. Ela tinha aberto os arquivos para os americanos. Então ela abriu os arquivos para nós. Começamos a consultar os arquivos pelo arquivo Vargas. Depois consultamos outros arquivos. Se você quiser, eu trouxe aqui o livro de Luciano. Aqui tem os arquivos que nós consultamos. Eu não me lembro direito. Arquivo Vargas, o arquivo de Barbosa Carneiro, Horta Barbosa, Lourival Fontes, Lúcio Meira, Ibá Jobim Meireles... Na ocasião, não era muito comum consultar arqui- 
vos privados. Nós consultávamos muito mais o arquivo público. Então fizemos essa pesquisa e entrevistas, coisa que também não era muito comum. Começamos a entrevistar as pessoas que participaram de tudo. Fomos entrevistando. E quem trabalhou nesse grupo que Luciano constituiu? Celina Vargas do Amaral Peixoto, que era estudante da PUC e foi trabalhar conosco. Alba Zaluar também foi nossa colega, Ayrton, Ana Maria Roiter. Muitas pessoas foram estagiárias nesse grupo.

T.C.L. Essa era a pesquisa coordenada pelo Maurício Vinhas de Queiroz, dos grupos multibilionários, ou era a pesquisa de tese de Luciano Martins?

A.A.A. Não. Depois é que se transformou na tese dele de doutorado de Estado, na França. Depois ele vai para a França e usa esse material para fazer a tese de doutorado. Eu acho que foi uma experiência. Eu queria lembrar também que não foi só o grupo de Luciano Martins. Tinha o grupo de Luciano Martins no Instituto de Ciências Sociais, o grupo de Maurício Vinhas de Queiroz, do qual Stella fazia parte...

T.C.L. E como era a dinâmica desses grupos? Eles se encontravam para discutir as pesquisas? Como essas pesquisas se articulavam?

A.A.A. Nós nos encontrávamos. Fazíamos reuniões para discutir o trabalho, como estava o andamento e o que estávamos fazendo. Nós fazíamos isso.

T.C.L. E as atividades do ICS tinham uma conexão forte com alguma instituição de ensino, como a própria UFRJ ou a PUC?

A.A.A. Não, não tinha nada a ver. Era totalmente distante das instituições. Era a pesquisa e só. Essas pessoas vinham como estagiários e faziam a pesquisa. Nós ensinávamos a fazer isto e aquilo, pedíamos para levantar dados e recomendávamos a leitura de tais e tais livros. Fizemos pesquisa sobre a siderúrgica de Volta Redonda, a criação da Petrobras, do BNDES e da indústria automobilística. Esses eram os temas que tratávamos, com cada um trabalhando lá.

T.C.L. Quais são as questões que estruturam esses temas? O que está sendo discutido nesse momento? Tem a questão do desenvolvimento?

A.A.A. Tem a questão do desenvolvimento, sim. No caso de Luciano, ele estava trabalhando com a industrialização, o processo de desenvolvimento industrial do Brasil, e estava muito preocupado com o papel do industrial, qual era o papel que esse industrial estava tendo nesse processo, o papel do industrial nacional. Falava-se muito sobre o papel do industrial estrangeiro. Ele então vai discutir o 
papel do industrial brasileiro, e nós trabalhávamos com esse industrial. Nós os entrevistávamos e investigávamos quem eram e de onde vinham. $\mathrm{Na}$ época, era algo novo para nós. Fernando Henrique Cardoso já estava trabalhando com isso e era muito ligado a Luciano Martins. Weffort... Eram frequentadores ali do instituto Fernando Henrique Cardoso, Maria da Conceição Tavares... Ela ia muito lá.

T.C.L. No Instituto de Ciências Sociais?

A.A.A. É. Ela ia lá e discutia conosco.

T.C.L. Eles iam como convidados para alguma atividade?

A.A.A. Não. Eles iam lá porque eram amigos de Luciano e queriam discutir o assunto. Luciano chamava. Fernando Henrique ia discutir o tema porque estava trabalhando com o processo de industrialização. Todos trabalhavam com isso. Conceição Tavares estava trabalhando também.

T.C.L. Celso Furtado também frequentava o instituto?

A.A.A. Celso Furtado era muito amigo de Luciano também. Conheci toda essa gente ali. Todos apareciam ali por causa dos temas que estavam sendo tratados.

T.C.L. É interessante, porque Fernando Henrique tem uma interpretação muito própria sobre como ele se posicionava nesse debate sobre o papel da burguesia nacional.

A.A.A. É, o papel da burguesia nacional. Exatamente.

T.C.L. De certa maneira, é uma discussão que está colocada ali. E como seria então essa tese de Luciano Martins nesse debate mais amplo sobre a burguesia nacional?

A.A.A. Ele quer mostrar exatamente como é um momento novo do Brasil, como esses novos empresários estão chegando. Eu trouxe até o livro aqui. Não sei se vocês conhecem. É a tese dele. Na tese, ele vai trabalhar exatamente com isso. Como é que o empresário chega nesse momento e começa a ter uma nova atitude e tomar uma posição importante no processo de desenvolvimento? Ele vai ter outro papel. Não vai só assistir. Ele vai ser um incentivador e investir muito. Começa o maior investimento do empresário industrial brasileiro.

T.C.L. E como funcionava em termos de recursos? Fazer pesquisa era difícil, especialmente na universidade do Brasil. 
A.A.A. Era dinheiro da universidade. Eu não me lembro muito bem, mas acho que Luciano tinha recursos de outras instituições. Tem que ver isso. Eu não tenho muita certeza, mas ele tinha recursos de outras instituições. Ele tinha muitos contatos e trazia mais recursos. Mas nós éramos todos contratados pela universidade. Nós éramos do Ministério da Educação.

T.C.L. O contrato era como pesquisador?

A.A.A. Isso, como pesquisador.

T.C.L. É um contrato que não existe mais nesses termos. E, de certa maneira, é uma forma disjuntiva, não é? Ou se é professor ou se é pesquisador? É isso?

A.A.A. Nós não éramos professores, e sim pesquisadores. Fazíamos pesquisa e etc. Eu não me lembro direito, mas chegou uma época em que junta a universidade. Essas datas são difíceis para mim, mas eu queria lembrar que junta a universidade, a Faculdade Nacional de Filosofia. Acho que é em I967. Aí os alunos de história vão para o ICS. Eu me lembro bem disso. Acho que foi em I967.

T.C.L. Com a reforma universitária, certo?

A.A.A. É, a história passou a fazer parte do Instituto de Filosofia e Ciências Sociais. Aí ela vem para a Marquês de Olinda. Nós éramos um grupo tranquilo. Todo mundo tinha sua salinha. Tinha o grupo de Maurício. Tinha o grupo de Pessoa de Queiroz. Eram três grupos de pesquisa: de Luciano, de Maurício e de Pessoa de Queiroz. Pessoa de Queiroz também fazia pesquisa na área econômica. Como eu disse, Maurício tinha estagiários como Gilberto, Yvonne e Hélio. E tinha Stella, que era assistente de Maurício e também fazia parte dos grupos econômicos. E tinha Pessoa de Queiroz, que logo depois foi embora para os Estados Unidos. Depois os alunos de história vão para o instituto. Você não pode imaginar o que era. A polícia chegava, e os meninos corriam para a nossa sala, porque eles faziam manifestações ali e tudo o mais. Aí a polícia vinha. Nós escondíamos os alunos. "Entra aqui. Fica ali." Nós escondíamos os meninos quando a polícia chegava e dizíamos que não tinha ninguém ali. Era uma confusão. Vocês não podem imaginar o que era. Era o período áureo da repressão, e os meninos faziam a maior confusão. Eles faziam a provocação e, quando a polícia chegava, eles corriam e se escondiam. Eles iam lá para a nossa sala e pediam ajuda, e nós os escondíamos.

T.C.L. Isso era na faculdade de história ou de ciências sociais?

A.A.A. Era história e ciências sociais. 
T.C.L. A filosofia não estava?

A.A.A. Eu me lembro que eles ficavam lá atrás. Nós tínhamos... Agora não tem mais. Hoje tem um prédio no lugar. Mas antes era uma casa. Atrás é que ficavam os alunos. O ensino ficava atrás e nós ficávamos na frente. Eu lembro que eles corriam, iam para a nossa sala e pediam para ficar ali. Era uma bagunça.

T.C.L. E a diretora era Marina São Paulo de Vasconcellos?

A.A.A. Olha, eu me lembro muito do doutor Evaristo de Moraes. Depois era a dona Marina Vasconcellos, que era uma figura maravilhosa, que nos ajudava e nos incentivava muito. Acho que foi na fase dela que se deu a fusão e essa coisa toda. Então foi isso. Não tenho muito o que falar. Eu queria me lembrar disso. Foi um período muito importante para a pesquisa de ciências sociais, do qual eu e Maria Luiza participamos como pesquisadoras com Luciano Martins. Agora, se vocês quiserem, tem os estagiários que fizeram parte disso. Nós ensinávamos e mandávamos fazer pesquisa nos arquivos públicos, e ele nos ajudavam nas entrevistas e faziam levantamento bibliográfico. Bom, nesse período todo, Luciano vai para a França fazer doutorado. Eu também, em I969. Aí junta tudo isso. Eu lembro que Celso Furtado incentivava muito ir para a França fazer doutorado. Ele, aliás, é quem faz o contato na França para eu ir fazer meu doutorado na École de Troisième Cycle. Luciano faz o doutorado de Estado, o Doctorat d’État, eu faço o Troisième Cycle. Fico na França até I973. Depois volto ao Brasil para acabar minha tese e só retorno à França para defender. Luciano voltou antes. Quando eu voltei, o instituto aqui tinha acabado.

T.C.L. Lá no Centro?

A.A.A. Ali na cidade, no Largo de São Francisco, onde era a escola politécnica.

T.C.L. Quando a senhora diz que era um momento muito importante da pesquisa em ciências sociais no Rio de Janeiro, o que se fazia em termos de pesquisa na cidade? Qual era o lugar do instituto no mundo das ciências sociais nesse período?

A.A.A. Tinha aquele instituto de ciências sociais em que se fazia pesquisa. Como era o nome? Era aquele que tinha Wanderley Guilherme dos Santos.

T.C.L. O Iseb?

A.A.A. Não, o Iseb é uma coisa. Até minha tese é sobre o Iseb. Não, depois do Iseb tem um instituto. 
T.C.L. O antigo Iuperj?

A.A.A. É o Iuperj. Aí eles vão fazer tudo. É isso que eu me lembro.

T.C.L. A senhora se lembra de algum tipo de interação ou contato com o Centro Latino-Americano de Pesquisa em Ciências Sociais?

A.A.A. Tivemos contato. Eu me lembro bem. Qual era o nome dele?

T.C.L. Manuel Diégues Júnior?

A.A.A. Isso, eu o conhecia bem.

T.C.L. E como era essa relação?

A.A.A. Muito boa. Nós tínhamos uma relação boa com eles. Discutíamos muito o trabalho que eles faziam também. O Instituto da América Latina era importante.

T.C.L. É curioso, porque tanto o Clapcs quanto o ICS, dois lugares importantes da pesquisa no Rio de Janeiro, eram desconectados do ensino.

A.A.A. É, os dois não tinham nada de ensino. Eram só centros de pesquisa.

T.C.L. Não havia nenhum esforço nesse sentido de interligar essas atividades e de trazer esses estudantes?

A.A.A. Não, nós trazíamos apenas estagiários. Quando precisávamos de um estagiário, íamos buscar na faculdade. Chegávamos lá e perguntávamos: “Quem conhece alguém que queira vir aqui?" Eu lembro que veio muito mais gente da PUC do que de outros lugares. Nossos estagiários vinham mais da PUC.

T.C.L. Existia alguma mediação específica?

A.A.A. É porque um conhecia o outro e indicava. Era mais por aí.

T.C.L. É que nós temos a impressão de que, no caso da Faculdade Nacional de Filosofia, como durante uns 20 anos, o catedrático efetivo foi o Hildebrando Leal... É uma figura sobre a qual nós conhecemos muito pouco, mas parece que ele não tinha nenhuma orientação de pesquisa na cadeira de sociologia. A senhora conheceu o Hildebrando? Como ele era? 
A.A.A. Conheci. Olha, ele era uma pessoa que não tinha nenhum... Eu lembro que, quando eu voltei da França e o instituto tinha acabado, eu fui lá para o Ifcs. Aquilo era uma tragédia, porque não tinha pesquisa. Acabou. Quando eu estava estudando lá, não tinha pesquisa. O que eu podia fazer? Agora, quando eu saí e fui trabalhar com Darcy Ribeiro, ele sim começava a fazer pesquisa. Quando eu fui aluna de Darcy, fui para Biblioteca Nacional e tudo o mais fazer pesquisa com ele. Isso como aluna.

T.C.L. Isso ainda no curso de história e geografia? A senhora se aproximou mais de Darcy?

A.A.A. Isso, no curso de história e geografia, e fui fazer pesquisa com Darcy. Yedda Linhares era uma pessoa que fazia pesquisa também, mas não era como nós fazíamos com Darcy. Ele mandava fazer um tema, fazer um levantamento na biblioteca e ver o arquivo tal. Isso não existia.

T.C.L. Como eram as aulas de Darcy Ribeiro?

A.A.A. Ele era muito criativo. Tinha uma criatividade muito grande e sempre inventava coisas. Você tinha que saber as novidades. Eu me entusiasmei com as aulas de Darcy. Eu ainda era aluna quando ele começa a me botar para fazer pesquisa em biblioteca e arquivo. Eu fazia pesquisa sobre índio. Quando acabei, ele me levou para o CBPE.

T.C.L. É interessante, porque era um trabalho de pesquisa arquivística, porque a cadeira dele era etnologia do Brasil. Mas não chega a ter nenhum trabalho de campo ou alguma articulação com o Museu Nacional?

A.A.A. Não.

T.C.L. Um traço também interessante desse período e que, em algumas versões da história das ciências sociais, é visto como negativo - embora não vejamos assim - era a profunda relação entre os pesquisadores, o pessoal de sociologia, e outras atividades, no campo cultural e político. O próprio Darcy Ribeiro também foi chefe de gabinete.

A.A.A. É, depois ele vai ser político.

T.C.L. O próprio Luciano Martins. Destacamos isso porque, por um acaso muito interessante, o Ifcs recebeu, há pouco tempo, o arquivo de Luciano Martins. Ele trabalhou como jornalista durante um tempo. 
A.A.A. É, ele foi jornalista do Jornal do Brasil.

T.C.L. Pois é. Esse era um traço dessa geração que marca de modo diferente as ciências sociais. Naquele momento, isso era visto como um problema? Porque existe uma tendência de ver como um problema, pensando em certas versões da história das ciências sociais. Vocês viam assim?

A.A.A. Não.

T.C.L. Esse problema se colocava para vocês nesse período? Era visto como uma incompatibilidade?

A.A.A. Não. Ninguém discutia isso. Eu nunca discuti isso.

T.C.L. Porque é como se fosse um entrave a uma tentativa de profissionalização.

A.A.A. Não. Por exemplo, Darcy Ribeiro foi um cara que teve um papel importante na antropologia durante um determinado momento e depois larga tudo. Ele vai criar a Universidade de Brasília e depois vira político.

T.C.L. Eu queria, se possível, explorar a experiência da senhora na Faculdade Nacional de Filosofia, pensando o curso de história e geografia. Muito pouco se sabe desses cursos nessa época. E eu estou pensando especialmente nas disciplinas e nos professores do curso de geografia. A senhora se lembra dessa experiência?

A.A.A. Olha, eu lembro que tinha um professor de geografia que era muito bom. Como ele se chamava mesmo?

T.C.L. Hilgard Sternberg, de geografia do Brasil.

A.A.A. É. Acho que era isso. Porque tinha umas pessoas muito ruins. Não queria nem falar isso, porque fica chato. Na história, tinha a Yedda Linhares. Era um curso excelente. Isso não tem dúvida nenhuma. Ela nos botava para pensar e fazer pesquisa. Pesquisa bibliográfica, é importante frisar. Ninguém fazia pesquisa. Agora, vocês sabem como era Hélio Viana. Era decorar o livro dele. Tinha um de história da América também.

T.C.L. Era Sílvio Júlio de Albuquerque Lima? A senhora teve aula com ele?

A.A.A. Tive. 
T.C.L. Como era Sílvio Júlio? Porque ele é dessas personagens pouco conhecidas.

A.A.A. Ele também não tinha nada de importante. Eram pessoas que não te transmitiam nada, que não despertavam nada. Eu me lembro disso. Agora, história com Yedda, sim. Nós chegávamos a brigar. Tinha Marina Vasconcellos, que era professora de antropologia. Darcy Ribeiro entra depois, já no final. Eram pessoas que te despertavam o interesse em pesquisa, em pensar e discutir. Os outros, não. Eu lembro que, com Hélio Viana, nós tínhamos que decorar o livro dele e repetir aquilo para ter nota. Em história da América também não tinha ninguém bom. Era ruim também. Então, quando tem professores que chegam e põem a coisa para cima, como Darcy Ribeiro e Yedda, que nos faziam pensar, que discutiam... Tinha também o Francisco Falcon, assistente de Yedda. Era outro que nos colocava para discutir.

T.C.L. A senhora conhecia os outros professores de ciências sociais dessa época, como Djacir Menezes?

A.A.A. Eu conheci, mas não fui aluna. De Djacir Menezes, fui aluna muito brevemente.

T.C.L. Carneiro Leão nessa época dava aula de didática e era o diretor da faculdade.

A.A.A. É, mas também não tinha a menor importância. Eram pessoas que não despertavam nada em você.

T.C.L. E havia alguma interação entre os cursos, entre alunos de ciências sociais, história e geografia? Havia algum trânsito entre as cadeiras?

A.A.A. Não. Praticamente nada. Tenho que pensar um pouco, porque não estou lembrando. De sociologia, tinha o Costa Pinto.

T.C.L. Que era da Faculdade Nacional de Ciências Econômicas, certo?

A.A.A. Mas o Costa Pinto era de sociologia lá do Ifcs.

T.C.L. Mas ele só vai ser catedrático em I958, certo?

A.A.A. É, eu me lembro do Costa Pinto como assistente. Mas eu não era aluna dele, era de história. Só conhecia porque era amiga de pessoas da área de ciências sociais. Por exemplo, Maria Luiza, que era de ciências sociais. Então nós discutíamos muito com pessoas da área. 
T.C.L. Quando a senhora diz que alguns professores davam aulas que despertavam o interesse e outros não, eu me pergunto sobre as clivagens político-ideológicas que também existiam no ambiente acadêmico.

A.A.A. É, claro. Tinha isso.

T.C.L. Hilgard Sternberg, por exemplo, ficou conhecido, ou pelo menos era tido, como um professor mais conservador. Era católico. Como era isso?

A.A.A. É. Tinha o Eremildo Vianna.

T.C.L. Como isso se dava? Como a senhora percebia isso?

A.A.A. Na época, isso para nós já era uma questão. Havia uma perseguição. Isso começa depois que eu saio da faculdade. Então veio ig64. É aí que começa. Mas já havia uma diferença em relação a quem era de direita, católico e essa coisa toda.

T.C.L. Havia essa marca de um professor católico? Isso estava colocado?

A.A.A. Estava, se defendiam posições católicas e tudo o mais.

T.C.L. Os cursos de ciências sociais e história funcionavam no mesmo prédio, na atual Casa de Itália?

A.A.A. Primeiro, sim. Depois história e ciências sociais vieram para cá. Depois voltou tudo para o Largo de São Francisco.

T.C.L. Não tinha então uma integração forte dos alunos em relação aos cursos e aos catedráticos?

A.A.A. Não. Não me lembro muito disso. Nós tínhamos contato, é isso.

T.C.L. Então a clivagem mais forte em termos políticos era com católicos (talvez alguns ex-integralistas) e comunistas?

A.A.A. Hélio Viana era de história do Brasil. Era um cara católico. Não sei se vocês sabem, mas era isso.

T.C.L. É interessante, porque, em meados dos anos I950, essas clivagens ainda estão colocadas na Universidade do Brasil. 
A.A.A. É. Enfim, eu tenho pouco a dizer. Não me lembro mais. Já faz tanto tempo, que já até esqueci. Mas aí foi isso. Quando eu volto da França, já está tudo no Largo de São Francisco. Eu voltei e fui me apresentar lá, depois do doutorado. Era o Eduardo Prado Mendonça o diretor? Eu tenho isso anotado, porque eu queria lembrar o nome dele. Era Eduardo Prado de Mendonça. Quando eu volto da França, ele era o diretor da Faculdade Nacional de Filosofia, que já era ali no Largo de São Francisco. Eu lembro que eu volto, depois de fazer minha tese sobre o Iseb, e vou falar com o Eduardo Prado. Ele vira para mim e diz: "A senhora pode saber que aqui não tem mais pesquisa nenhuma. A senhora aqui vai dar aula. Não tem mais pesquisa nenhuma." Era assim. Aí eu fui dar aula. Não tinha pesquisa nenhuma. Eu brigava e falava com os alunos para pensarmos em fazer alguma coisa. Mas não, só podia dar aula, não podia fazer pesquisa.

T.C.L. E já era a estrutura atual de departamentos, certo?

A.A.A. Eu era do Departamento de Ciências Sociais.

T.C.L. É muito interessante sua pesquisa pensar a atuação do Iseb. Mas isso parte de que discussão? Qual é o contexto desse interesse em pensar a atuação do Iseb? Está ligada a alguma forma de avaliar criticamente a visão do Iseb sobre o desenvolvimento?

A.A.A. É sobre o desenvolvimento. Era uma discussão que eu fazia muito com Luciano Martins sobre o desenvolvimento. É um grupo de intelectuais que quer discutir e levar adiante o desenvolvimento brasileiro. Eu escolho o Iseb como tese. Vou fazer a tese e venho para cá. Saio da França e passo uns meses aqui fazendo entrevistas com todo o pessoal do Iseb. E aí, quando eu volto da França, a Faculdade Nacional de Filosofia não tinha mais pesquisa. "Não tem pesquisa. Você vai dar aula." Eu lembro que isso me chocou terrivelmente, porque eu estava no instituto aqui, fazendo pesquisa, e fui para a França também fazer pesquisa. Toda a minha experiência na França foi fazendo pesquisa. E, quando chego aqui, me dizem: "Vai dar aula. Não tem nada de pesquisa." Isso foi em I973 ou I974, quando eu volto.

T.C.L. É interessante porque o ICS, salvo engano, é pensado desde I95 I e criado em I958. O Iseb, nesse momento, já é uma instituição muito importante. Não havia então uma dinâmica de concorrência entre o Iseb e o ICS?

A.A.A. Não.

T.C.L. Como é que se dava essa relação em termos político-ideológicos? Porque aparentemente, no ICS, havia uma postura mais crítica ao desenvolvimentismo. 
A.A.A. É, mas não tem essa coisa. Pelo contrário. O pessoal do atual Ifcs era contra o pessoal do Iseb, lógico.

T.C.L. Mas a equipe do ICS não tinha nenhuma relação?

A.A.A. Bom, aí tinha entre os professores, seus colegas. Isso é uma coisa. Mas a direção, o que te orienta, aí era contra. É isso que eu estou dizendo. Colegas não. Nós éramos contra aquilo tudo que estava sendo feito, eu, Maria Luiza, Stella, todo mundo. Vocês têm que ouvir Stella.

T.C.L. Claro, nós estamos prevendo uma conversa com Stella também.

A.A.A. Porque Stella trabalhou e depois foi para o Ifcs.

T.C.L. A senhora chegou a frequentar cursos, seminários e palestras no Iseb?

A.A.A. Não.

T.C.L. Porque havia sessões abertas também.

A.A.A. Eu sei. Eu conhecia antes e tal, mas nunca fui aluna do Iseb. Fui é fazer pesquisa sobre ele.

T.C.L. Mas uma coisa que chama muita atenção no próprio ICS é que essa é uma estrutura totalmente interdisciplinar. Como exemplo, podemos pegar o conselho diretor de I967 do ICS. Temos, como presidente, Evaristo de Moraes Filho, que era da Faculdade Nacional de Direito (mas também dava aulas na Faculdade Nacional de Filosofia), Roberto Cardoso de Oliveira (do Museu Nacional) como vice-presidente e os conselheiros de várias faculdades. Temos ainda Themístocles Cavalcanti, Antônio Garcia Neto, Marina São Paulo de Vasconcellos, José Ferreira de Souza e o corpo técnico de pesquisadores. Essa divulgação interdisciplinar de fato era sentida no cotidiano da instituição? Era de fato uma perspectiva de análise?

A.A.A. Era. Eu acho que sim. Nós tínhamos uma visão de discussão muito grande.

T.C.L. Era muito interessante, porque juntava economia, direito, ciências sociais, o Museu Nacional...

A.A.A. Antropologia. Nós tínhamos uma visão bem ampla e discutíamos muito. Éramos muito atuantes naquela época. Já faz muitos anos. 
T.C.L. De fato, é uma concepção de uma visão mais integrada em relação ao próprio sentido do desenvolvimento. É como se o próprio objeto requeresse uma abordagem interdisciplinar. Isso aparece também bastante no Clapcs e no próprio CBPE, nas pesquisas. E isso está colocado no ICS.

\section{A.A.A. É.}

T.C.L. É um ponto interessante. Pensando em São Paulo, a marcação disciplinar, sobretudo em relação à sociologia, foi muito mais definida do que no Rio.

A.A.A. É, isso nem se discute. Nem vamos discutir isso.

T.C.L. É interessante ver o que se ganha e o que se perde em cada um desses projetos de pesquisa.

\section{A.A.A. É.}

T.C.L. Outro ponto importante sobre o qual queríamos conversar é a dissolução do ICS. Então o ICS de fato é dissolvido com a reforma universitária, cedendo lugar ao Ifcs. Como a senhora avaliaria o impacto do ICS tanto para a pesquisa no Rio de Janeiro quanto para as gerações seguintes que vão criar em outras bases as ciências sociais aqui no Rio?

A.A.A. Pois é, como eu tinha dito. Eu estou falando do ICS. É um grupo de pesquisa, claramente o grupo de Luciano, que forma gente. O Cpdoc é criado por Celina, que foi estagiária lá. Nós fazíamos pesquisa no arquivo do avô dela. Eu fazia pesquisa no arquivo de dona Alzira. Ela dizia: "Vocês chegam depois do almoço e saem antes do jantar." Nós chegávamos e passávamos o dia inteiro lá. Ela trazia os documentos e nós consultávamos todos. Tinha outros arquivos também. Eu não vou me lembrar de tudo que fizemos lá. Era uma loucura. E o debate que existia. Eu lembro que era assim. Fernando Henrique Cardoso era uma pessoa muito importante para nós. Francisco Weffort, Conceição Tavares. Eu me lembro desses no momento, mas tinha outros. Eram pessoas com as quais nós discutíamos. O ICS era um lugar onde se tinha um debate. Tinha o grupo que trabalhava mais com economia. Stella pode falar mais sobre isso. Era o grupo dela. O grupo de Luciano trabalhava com sociologia. Nós trabalhávamos com sociologia, história e tal. E tinha o grupo que trabalhava mais com os aspectos econômicos do desenvolvimento. Isso acaba lá, mas depois se recompõe. Quando eu volto, é uma desgraça aquilo. Não tinha pesquisa nenhuma. Não podia fazer pesquisa nenhuma, só dar aula. Depois eu acho que as coisas vão mudando. Os outros diretores vão alterando aquela situação. 
T.C.L. De todo modo, como a senhora relatou, foi um espaço muito importante de socialização e pesquisa de uma geração que vai ser fundamental para a própria construção das ciências sociais no Rio de Janeiro nos anos I970 e I980.

A.A.A. Eu acho que sim. Esse grupo... Tem o grupo do Iuperj, que é muito importante e que vai fazer pesquisa no Rio de Janeiro.

T.C.L. Algum deles esteve no ICS, dessa primeira geração do Iuperj?

A.A.A. Não, eu acho que não. Nenhum deles. É outra turma. Tinha também um pessoal da PUC importante, que vai fazer pesquisa no Rio de Janeiro. Aí a coisa começa a evoluir. Vocês é que vão fazer essa pesquisa.

T.C.L. Eu acho que se tem um cenário que vai se tornando mais complexo.

A.A.A. É. Depois vem a Uerj, que também vai fazer pesquisa, a UFF, de Niterói... E vai se diversificando ao longos dos anos. Vocês é que vão fazer a pesquisa para saber isso.

T.C.L. É interessante porque as instituições com esse perfil de pesquisa interdisciplinar como o ICS, o Clapcs e o CBPE vão cedendo lugar a passos mais disciplinares e mais ligados à universidade, um fenômeno mais assentado de institucionalização.

A.A.A. É.

T.C.L. Mas esse momento é muito rico, com esses arranjos bem diferentes em relação ao que aconteceu depois. É interessante também pensar que a senhora diz que, em história, não se fazia pesquisa arquivística, mas a senhora faz pesquisa documental a partir de um trabalho em sociologia, com Luciano Martins, em arquivos pessoais. Eu penso em termos de reflexão metodológica. Tomando os americanos como exemplo, desde os anos I930 e I940, nas ciências sociais, eles falam de história de vida, da importância de documentos pessoais, cartas e etc. Havia alguma discussão nesse terreno nesse grupo? Como era a reflexão metodológica? Vocês estão lá fazendo trabalho com o arquivo da Alzira Vargas.

A.A.A. Eram vários arquivos. No nosso trabalho, nós víamos como eram esses empresários, como era a atitude deles em relação ao desenvolvimento, como eles se colocavam no desenvolvimento, como eles se viam nisso e como o Estado via isso, como o Estado dava a possibilidade para que eles entrassem nisso. Acho que Luciano está preocupado com isso. A partir dos anos I950, começa uma mudança no desenvolvimento brasileiro. A partir da década de 
I950 e I960, os empresários brasileiros começam a tomar uma posição e a ter um papel mais importante na criação de novas possibilidades e em novos investimentos. Eles vão fazer novos investimentos em novas áreas.

T.C.L. A própria expressão "empresários brasileiros" já sugere um deslocamento em relação à expressão "burguesia nacional" como um ator muito unificado que faria uma revolução burguesa como uma classe. Dá um deslocamento em relação ao espaço imaginado da burguesia nacional.

\section{A.A.A. É.}

T.C.L. Quais são as conclusões em termos gerais dessa pesquisa do Luciano? Teve repercussão? Pensando em termos de discussão mais ampla e na inserção maior para além da universidade.

A.A.A. Eu acho que o papel dele foi importante. Agora, se houve divulgação? Eu acho que teve. Entre os pesquisadores, Luciano teve um papel importante. A pesquisa dele foi importante. Mas, naquela época, não tinha esse papel que tem hoje. Não podemos pensar nisso. Não tinha assim uma grande divulgação. Era aquele grupo de pesquisadores que sabia que ele estava fazendo aquela pesquisa, que ia e que se interessava. Era limitado. Pensa assim. Não era como hoje, que você faz uma pesquisa e tem divulgação. Não tinha, não.

T.C.L. De alguma forma, a pesquisa conseguiu interpelar o debate político? Pensando mesmo nessa inserção mais ampla dos cientistas sociais nos jornais.

A.A.A. Não, não tinha. Se você fizer uma pesquisa de jornal dessa época, não vai ver nada. Eu nunca fui fazer essa pesquisa, mas tenho certeza de que não se falava disso. Era tudo muito limitado nos anos i 950 e ig6o. A coisa começa a mudar depois. Se vocês quiserem fazer um levantamento de jornais da época, vão ver que não tinha.

T.C.L. Não, mas imaginamos que tenha sido uma experiência fundamental e muito diferente em relação ao que se fazia antes e ao que se fez depois em ciências sociais. Abrir a caixa-preta do ICS é fundamental.

A.A.A. Eu acho que mudou muito. A coisa vai mudar a partir dos anos I960. Mas antes era uma coisa limitada. Mesmo em São Paulo, com um grupo mais conhecido, que contava com Fernando Henrique, Florestan Fernandes e aquela turma toda que vai impulsionar as ciências sociais. Aqui no Rio, a coisa é mais devagar. Quem nós tínhamos aqui? O Costa Pinto. O nome que nós tínhamos nas ciências sociais, na sociologia, era o Costa Pinto. 
T.C.L. Guerreiro Ramos?

A.A.A. Que era uma pessoa inteligente, mas que não fazia a menor divulgação das coisas. Ele não trazia os alunos para a pesquisa, não fazia nada disso. Pessoalmente, eu acho o Costa Pinto uma pessoa inteligente, competente, tudo isso. Agora, se pararmos para pensar no que ele fez com os grupos, se criou grupos ou se fez estudos, que eu me lembre, não teve nada disso. Já outros professores faziam isso, como Darcy Ribeiro, por exemplo. Os outros professores davam aula. O pesquisador dava sua aulinha e acabou. Às vezes fazia até uma pesquisa, mas não tinha uma coisa de envolver os alunos. Mas Luciano Martins fez isso. Ele fez uma pesquisa, envolveu estudantes e tal. Era diferente.

T.C.L. Luciano Martins era muito ligado ao Costa Pinto, não? Era uma importante aposta.

A.A.A. Era. Também era ligado. Tinha Maurício Vinhas de Queiroz também no instituto. Aí tem que ver essa gente toda, como fazia isso. Eu acho que ainda era muito limitado. A pesquisa vai se desenvolvendo ao longo dos anos e tomando um outro rumo. Então Capes e CNPq vão começar a financiar pesquisas. Estudantes vão participar e tal. É outra coisa. Os alunos começam a se interessar. Eu acho que é diferente. Olha, eu já falei muito. Não tenho mais o que falar.

T.C.L. Eu queria fazer uma última pergunta sobre a sua experiência docente já no final dos anos I970 e depois nos anos I980. Sei que é um período longo. Como foi sua experiência no Ifcs como professora? Pesquisa estava fora de cogitação?

A.A.A. Aí eu vim para o Cpdoc. Eu vim fazer pesquisa aqui e trouxe os alunos para cá. Mas, lá no instituto, eu dava aula. Eu gostei. Não vou dizer que não gostei. Gostei sim. Foi uma experiência boa. Eu dava aula de sociologia e dei coisas boas. Tive uma boa experiência, mas não dava para fazer pesquisa. Eu vim fazer pesquisa aqui. Foi aqui que eu comecei a fazer pesquisa. Lá tinha essa coisa. Estou falando de Eduardo Prado virando para mim e dizendo: "A senhora sabe que vai dar aula, não é? Não tem nada que fazer pesquisa aqui." Para mim, foi um choque. Não tinha que fazer pesquisa nenhuma, lá só se dava aula. Depois a coisa começa a mudar devagar. Mas eu gostei de ter dado aula lá. Foi uma boa experiência. Você tem que preparar a aula e pensar coisas. Tive muitas ideias lá, dando aula. Para mim, isso foi importante. Mas eu vim fazer pesquisa aqui. 


\section{NOTA}

I Estudos que, além dos contrastes, têm enfocado similitudes ou conexões entre as experiências do Rio de Janeiro e de São Paulo no terreno das ciências sociais, explorando especialmente a dimensão cognitiva da produção sociológica ocorrida nas duas cidades, encontram-se, por exemplo, em Lima (I999), Villas Bôas (2006), Botelho (2007), (Brasil Jr., 2013) e Maio \& Lopes (2015).

Thiago da Costa Lopes é graduado em ciências sociais pelo Instituto de Filosofia e Ciências Sociais da UFRJ e doutor em história pelo Programa de Pós-Graduação em História das Ciências e da Saúde da Casa de Oswaldo Cruz/Fiocruz. Sua tese, intitulada Comunitarismo, sociologia rural e diplomacia cultural nas relações Brasil/EUA (I930-I950), foi vencedora do Prêmio Capes-Fulbright de Tese de 20 Ig. 


\section{REFERÊNCIAS}

Abreu, Alzira Alves de. (2012). Depoimento. Rio de Janeiro: Cpdoc/FGV. Disponível em: <https://cpdoc.fgv.br/sites/ default/files/cientistas_sociais/alzira_abreu/TranscricaoAlziraAbreu.pdf>. Acesso em: Io jan. 2019.

Abreu, Alzira Alves de. (1975). Nationalisme et action politique au Brésil: une étude sur l'Iseb. Thèse pour le doctorat

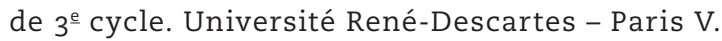

Almeida, Maria Hermínia Tavares de. (200I) [1989]. Dilemas da institucionalização das ciências sociais no Rio de Janeiro. In: Miceli, Sergio (ed.). História das ciências sociais no Brasil, v.I, 2 ed. São Paulo: Idesp/Sumaré/Fapesp, p. 223-256.

Amorim, Maria Stella. (I999). Costa Pinto e a missão sociológica. In: Maio, Marcos Chor \& Villas Bôas, Glaucia (eds.). Ideais de modernidade e sociologia no Brasil: ensaios sobre Luiz Aguiar Costa Pinto. Porto Alegre: Ed. da UFRGS, p. 23-38.

Botelho, André. (2007). Sequências de uma sociologia política brasileira. Dados, 50/I, p. 49-82.

Brasil Jr., Antonio. (2013). A reinvenção da sociologia da modernização: Luiz Costa Pinto e Florestan Fernandes (I950-I970). Trabalho, Educação e Saúde, II/I, p. 229-249.

Fávero, Maria de Lourdes de A. (ed.). (I989). Faculdade Nacional de Filosofia: projeto ou trama universitária?, v. I. Rio de Janeiro: UFRJ.

Ferreira, Marieta de Moraes. (2013). A história como ofício: a constituição de um campo disciplinar. Rio de Janeiro: Ed. FGV. Lima, Nísia Trindade. (I999). Um sertão chamado Brasil: intelectuais e representação geográfica da identidade nacional. Rio de Janeiro: Iuperj/Ucam/Revan.

Maio, Marcos Chor. (1997). A história do Projeto Unesco: estudos raciais e ciências sociais no Brasil. Tese (Doutorado em Ciência Política). Instituto Universitário de Pesquisas do Rio de Janeiro.

Maio, Marcos Chor \& Lopes, Thiago da Costa. (2015). 'For the establishment of the social disciplines as sciences': Donald Pierson e as ciências sociais no Rio de Janeiro (I942-I949). Sociologia \& Antropologia, 5/2, p. 343-380. 
Martins, Luciano. (1968). Industrialização, burguesia nacional e desenvolvimento. Rio de Janeiro: Saga.

Oliveira, Lucia Lippi. (I995). As ciências no Rio de Janeiro. In: Miceli, Sergio (ed.). História das ciências sociais no Brasil, v. 2. São Paulo, Idesp/Sumaré/Fapesp.

Peixoto, Fernanda Arêas. (200I) [1989]. Franceses e norteamericanos nas ciências sociais brasileiras, I930-I960. In: Miceli, Sergio. (ed.). História das ciências sociais no Brasil, v.I, 2 ed. São Paulo: Sumaré/Fapesp, p. 477-532.

Rodrigues, Leôncio Martins. (2009). Fernando Henrique Cardoso: a ciência e a política como vocação. In: Botelho, André \& Schwarcz, Lilia Moritz (eds.). Um enigma chamado Brasil: 29 intérpretes e um país. São Paulo: Companhia das Letras, p. 390-405.

Schwartzman, Simon; Bomeny, Helena Maria Bousquet \& Costa, Vanda Maria Ribeiro. (I984). Tempos de Capanema. São Paulo: USP/Paz \& Terra.

Villas Bôas, Glaucia. (2019). 80 anos de ciências sociais na UFRJ: relembrando o pioneirismo dos projetos Grupos Econômicos (I962) e Trabalhadores Cariocas (I987). Sociologia \& Antropologia, 9/I, p. 297-3I2.

Villas Bôas, Glaucia. (2006). Mudança provocada: passadoe futuro no pensamento sociológico brasileiro. Rio de Janeiro: Editora FGV. 


\section{O INSTITUTO DE CIÊNCIAS SOCIAIS E A SOCIOLOGIA NO RIO DE JANEIRO: ENTREVISTA COM ALZIRA ALVES DE ABREU}

\section{Resumo}

A entrevista com Alzira Alves de Abreu faz parte de uma iniciativa mais ampla, promovida por S\&A, de rememorar a história do curso de ciências sociais na Universidade Federal do Rio de Janeiro, que completou 80 anos em 20I9. A trajetória de Alzira se entrelaça com momentos significativos por que passaram as ciências sociais no Rio de Janeiro em seus esforços de institucionalização acadêmica e consolidação enquanto campo disciplinar, especialmente com as atividades investigativas conduzidas no interior do Instituto de Ciências Sociais (ICS), centro de pesquisas da antiga Universidade do Brasil (atual UFRJ), criado em I958. Nesse sentido, seu depoimento, além de constituir fonte importante para o resgate da memória da instituição, fornece pistas sugestivas para os estudiosos interessados em ampliar a compreensão que se tem da história daquelas disciplinas na cidade.

\section{THE INSTITUTE OF SOCIAL SCIENCES AND SOCIOLOGY IN RIO DE JANEIRO: INTERVIEW WITH ALZIRA ALVES DE ABREU}

Abstract

The interview with Alzira Alves de Abreu forms part of a broader initiative by S\&A to record the history of the social sciences course at the Federal University of Rio de Janeiro, which completed 80 years in 2019. Alzira's trajectory is interwoven with some of the key moments experienced by the social sciences in Rio de Janeiro in their efforts to achieve academic institutionalization and consolidation as a disciplinary field, especially with the investigative activities pursued at the Institute of Social Sciences (ICS), a research centre of the former University of Brazil (now UFRJ), created in I958. As well as constituting an important source for the recovery of the institution's memory, her testimony provides tantalizing leads for scholars interested in expanding our understanding of the history of these disciplines in the city.

\section{Palavras-chave}

Ciências sociais no Rio de Janeiro;

Alzira Alves de Abreu; Instituto de Ciências Sociais; Universidade Federal do Rio de Janeiro.

\section{Keywords}

Social sciences in Rio de Janeiro;

Alzira Alves de Abreu; Institute of Social Sciences; Federal University of Rio de Janeiro. 